\title{
Wentilactone A as a novel potential antitumor agent induces apoptosis and G2/M arrest of human lung carcinoma cells, and is mediated by HRas-GTP accumulation to excessively activate the Ras/Raf/ERKJ p53-p21 pathway
}

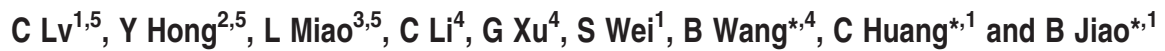

Chemotherapy remains the common therapeutic for patients with lung cancer. Novel, selective antitumor agents are pressingly needed. This study is the first to investigate a different, however, effective antitumor drug candidate Wentilactone A (WA) for its development as a novel agent. In NCl-H460 and NCl-H446 cell lines, WA triggered G2/M phase arrest and mitochondrial-related apoptosis, accompanying the accumulation of reactive oxygen species (ROS). It also induced activation of mitogen-activated protein kinase and p53 and increased expression of p21. When we pre-treated cells with ERK, JNK, p38, p53 inhibitor or NAC followed by WA treatment, only ERK and p53 inhibitors blocked WA-induced apoptosis and G2/M arrest. We further observed Ras (HRas, KRas and NRas) and Raf activation, and found that WA treatment increased HRas-Raf activation. Knockdown of HRas by using small interfering RNA (siRNA) abolished WA-induced apoptosis and G2/M arrest. HRas siRNA also halted Raf, ERK, p53 activation and p21 accumulation. Molecular docking analysis suggested that WA could bind to HRas-GTP, causing accumulation of Ras-GTP and excessive activation of Raf/ERK/p53-p21. The direct binding affinity was confirmed by surface plasmon resonance (SPR). In vivo, WA suppressed tumor growth without adverse toxicity and presented the same mechanism as that in vitro. Taken together, these findings suggest WA as a promising novel, potent and selective antitumor drug candidate for lung cancer.

Cell Death and Disease (2013) 4, e952; doi:10.1038/cddis.2013.484; published online 5 December 2013

Subject Category: Cancer

Lung cancer is the leading cause of cancer-related deaths worldwide. ${ }^{1}$ There are two main types of lung cancers, nonsmall-cell lung cancer (NSCLC) and small-cell lung cancer (SCLC). NSCLC is the common type of lung cancer and constitutes about $80 \%$ of all lung cancer cases. Although surgery is the only curative treatment of NSCLC, fewer than $20 \%$ of tumors can be radically resected. ${ }^{2}$ SCLC is less common and accounts for $20 \%$ of cases, but as this type of lung cancer grows quickly and is likely to spread, it is more difficult to cure by surgical resection. ${ }^{3}$ Therefore, chemotherapy remains common for patients with NSCLC or SCLC. ${ }^{4}$ Although systemic chemotherapy has been reducing the lung cancer mortality, both dose-limiting toxicity and poor disease progression remain inevitable. ${ }^{5}$ In recent decades, newly effective therapeutic treatments or novel compounds that can target certain molecular pathways used in the multistep carcinogenesis process of NSCLC have been explored; however, not for SCLC. ${ }^{6,7}$

The Ras family, containing $\mathrm{H}$-(or Ha-) Ras, K-(or Ki-) Ras and N-Ras, is commonly considered to be oncogenes; the Ras/Raf/ERK pathway is thought to be functional downstream of the epidermal growth-factor receptor (EGFR), which has been associated with a more aggressive disease or poor prognosis in a variety of cancer systems including lung

\footnotetext{
${ }^{1}$ Department of Biochemistry and Molecular Biology, Second Military Medical University, Shanghai 200433, China; ${ }^{2}$ Teaching and Research Office of Chinese Materia Medica, College of Pharmaceutical Sciences, Zhejiang Chinese Medical University, Hangzhou, Zhejiang 310052, China; ${ }^{3}$ Department of Pharmacology, School of Pharmacy and Institute of Biomedical Sciences, Fudan University, Shanghai 200032, China and ${ }^{4}$ Key Laboratory of Experimental Marine Biology, Institute of Oceanology, Chinese Academy of Sciences, Qingdao 266071, China

${ }^{*}$ Corresponding authors: B Wang, Key Laboratory of Experimental Marine Biology, Institute of Oceanology, Chinese Academy of Sciences, 7 Nanhai Road, Qingdao 266071, China. Tel: +86 0532 82898553; Fax: +86 0532 82898612; E-mail: wangbingui@gmail.com

or C Huang, Department of Biochemistry and Molecular Biology, Second Military Medical University, Xiangyin Road No. 800, Yangpu District, Shanghai 200433 , China. Tel: +86 2181870970 8002; Fax: +86 21 65334333; E-mail: huangcaiguo@ hotmail.com

or B Jiao, Faculty of Basic Medicine, Second Military Medical University, Xiangyin Road No. 800, Yangpu District, Shanghai 200433, China. Tel: +86 21 818709708001 ; Fax: +86 21 65334333; E-mail: jiaobh@ live.cn

${ }^{5}$ These authors contributed equally to this work.

Keywords: Wentilactone A; novel antitumor agent; lung cancer; Ras/Raf/ERK/p53-p21 pathway

Abbreviations: NSCLC, non-small-cell lung carcinoma; SCLC, small-cell carcinoma; HUVEC, human umbilical vein endothelial cell; DMSO, dimethyl sulfoxide; DAPI, 4',6-diamidino-2-phenylindole JC-1, 5,5',6,6'-tetrachloro-1,1',3,3'-tetraethyl-imidacarbocyanine iodide; z-VAD-fmk, caspase inhibitor N-benzyloxycarbonyl-Val-Ala-Aspfluoromethylketone; ERK, extracellular signal-regulated kinase; JNK, c-Jun NH2-terminal kinase; SAPK, Socialist Autonomous Province of Kosovo; MAPK, mitogenactivated protein kinase; GAP, GTPase activating protein; GEF, guanine-nucleotide-exchange factor; SPR, surface plasmon resonance; ROS, reactive oxygen species; NAC, $N$-acetylcysteine

Received 09.7.13; revised 30.10.13; accepted 04.11.13; Edited by D Aberdam
} 
cancer. ${ }^{8}$ However, it is now clear that oncogenic Ras can also deregulate apoptosis. There has been an increasing appreciation that Ras, and other oncogenes, paradoxically induce both pro- and anti-apoptotic signaling. The ultimate outcome of these contradictory signals depends greatly on the cell type and environment. Throughout the past 10-15 years, reports have suggested that activation of Ras proteins can have detrimental effects on mammalian cells, ultimately leading to death by apoptosis or other mechanisms. ${ }^{9}$ Furthermore, activation of Raf and/or ERK has been observed to increase cell death in studies of commonly used chemotherapy agents, for example, cis-diamminedichloroplatinum (II) (cisplatin), ${ }^{10}$ paclitaxel $^{11}$ and etoposide. ${ }^{12}$ Furthermore, combining chemotherapy with EGFR inhibitors in NSCLC has not produced a survival advantage. Therefore, the molecular mechanism of anticancer agents interacting with the Ras/Raf/ERK pathway is still unclear; clarifying it could lead to the identification of new molecular targets that might be manipulated to trigger cell death in cancer cells.

We have reported that a series of tetranorditerpenoids including asperolides $\mathrm{A}-\mathrm{C}$, Wentilactones $\mathrm{A}$ and $\mathrm{B}$ isolated from a marine-derived endophytic fungus, Aspergillus wentii $\mathrm{EN}-48$, have cytotoxic activities against various human tumor cell lines. ${ }^{13-15}$ We report here that EN-48-56, known as Wentilactone A (WA), exerts a significantly inhibitory effect on the lung carcinoma cell lines $\mathrm{NCl}-\mathrm{H} 460$ and $\mathrm{NCl}-\mathrm{H} 446$ without markedly inhibiting the proliferation of normal HUVECs. Furthermore, WA has the opposite molecular mechanism to EGFR inhibitors. It directly targets HRas-GTP and excessively activates the Ras/Raf/ERK pathway, which initiates apoptosis and G2/M phase arrest via p53-p21 participation and stabilization. In vivo, WA is also effective in inhibition of tumor xenograft growth and is safer than cisplatin. All of these present the potential use of WA to treat NSCLC and SCLC.

\section{Results}

WA inhibits cell proliferation and colony formation in $\mathrm{NCl}-\mathrm{H} 460$ and $\mathrm{NCl}-\mathrm{H} 446$ cells. As shown in Figure 1b, WA inhibited cell growth in both cancer cell lines in a dosedependent manner. The $\mathrm{IC}_{50}$ value of WA toward $\mathrm{NCl}-\mathrm{H} 460$ cell viability was $5.56 \pm 0.89 \mu \mathrm{M}$, and that toward $\mathrm{NCl}-\mathrm{H} 446 \mathrm{~s}$ was $1.90 \pm 1.30 \mu \mathrm{M}$ after $48 \mathrm{~h}$. However, WA did not show markedly inhibition of HUVECs. Additional clonogenic assays also indicated that WA suppressed the ability of a singlecarcinoma cell growth into a colony. Clonogenicity of both cancer cell lines was reduced in a concentration-dependent manner after exposure to WA (Figure 1c).

WA induces mitochondrial-related apoptosis in $\mathrm{NCl}-$ $\mathrm{H} 460$ and $\mathrm{NCl}-\mathrm{H} 446$ cells. We next assessed the effect of WA on the induction of apoptosis in $\mathrm{NCl}-\mathrm{H} 460$ and $\mathrm{NCl}-$ H446. Apoptotic cells with nuclear condensation and fragmentation can be visualized by DAPI staining. The photographs in Figure $2 \mathrm{a}$ show the results of $48 \mathrm{~h}$ treatment with $10 \mu \mathrm{M}$ WA. Annexin V-FITC/PI double stain was used to make a quantitative evaluation of apoptosis. Compared with the control group $(0.1 \%$ DMSO $), 10 \mu \mathrm{M}$ WA triggered apoptosis of $\mathrm{NCl}-\mathrm{H} 460$ and $\mathrm{NCl}-\mathrm{H} 446$ cells in a timedependent manner; $29.65 \pm 7.91 \%$ and $47.34 \pm 7.36 \%$ apoptosis at $48 \mathrm{~h}$ was induced, respectively (Figure $2 \mathrm{a}$ ).

To investigate the mitochondrial apoptotic events involved in WA-induced apoptosis, we tested the changes of the mitochondrial membrane potential $(\Delta \Psi \mathrm{m})$, bcl-2 family proteins, cytochrome $c$ release, proteolytic cleavage of procaspase and the effect of a general caspase inhibitor (z-VAD-fmk). The loss of $\Delta \Psi \mathrm{m}$, which was measured by $\mathrm{JC}-1$, can be tested after exposure of cells to $10 \mu \mathrm{M}$ WA in both cells, especially in $\mathrm{NCl}-$ H446 cells (Figure 2b). To further confirm whether WA-induced cell apoptotic death was caspase dependent, a general caspase inhibitor, z-VAD-fmk, was used. As indicated in Figure 2c, the addition of z-VAD-fmk reduced the apoptotic response from 27.89 to $10.73 \%$ in $\mathrm{NCl}-\mathrm{H} 460$ cells and from 54.79 to $10.32 \%$ in $\mathrm{NCl}-\mathrm{H} 446$ cells after $48 \mathrm{~h}$. Immunoblot analysis showed that treatment of $\mathrm{NCl}-\mathrm{H} 460$ and $\mathrm{NCl}-\mathrm{H} 446$ cells with $10 \mu \mathrm{M}$ WA increased bax and bad protein levels and, in contrast, decreased bcl-2 and Mcl-1 levels in a time-dependent manner. Consistently, cytochrome $c$ was released and cleavage of procaspase- $3 / 7$ and

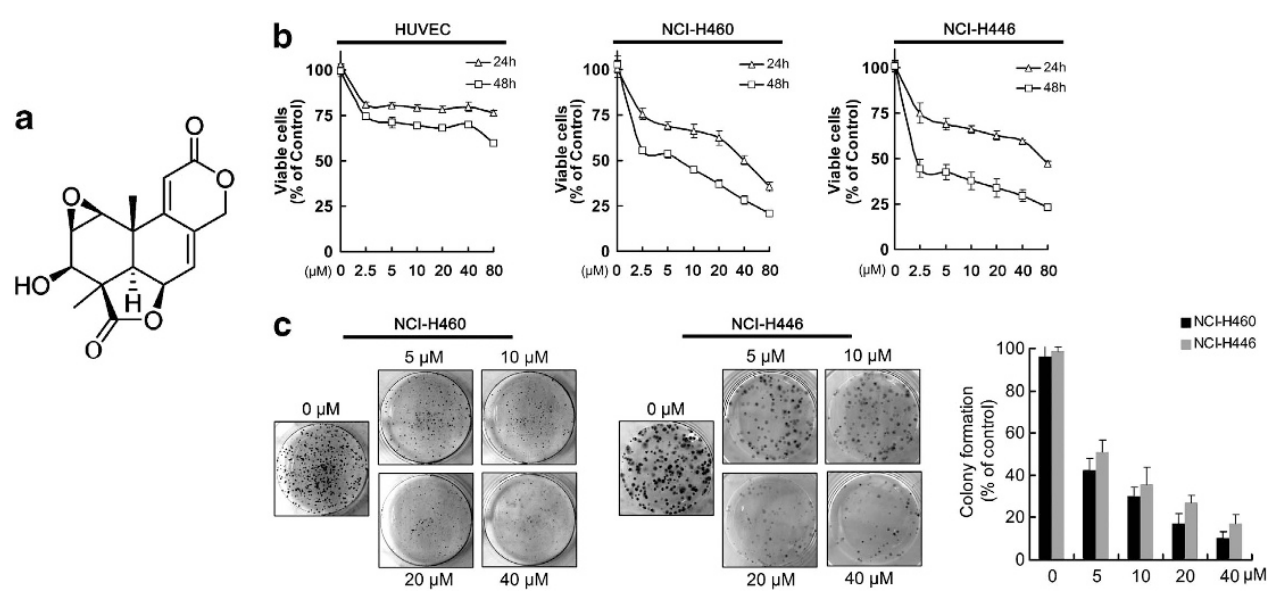

Figure 1 The effects of Wentilactone A (WA) on cell growth inhibition and colony formation. (a) Chemical structure of Wentilactone A. (b) HUVEC and human lung carcinoma cells ( $\mathrm{NCl}-\mathrm{H} 460$ and NCl-H446 cells) were treated with $0,2.5,5,10,20,40,80 \mu \mathrm{M}$ of WA for 24 and $48 \mathrm{~h}$, respectively. Cell viability was detected by MTT assay. (c) Effect of WA on the number of colony-forming cells as evaluated by clonogenic assay. Colonies were stained with trypan blue. Values are means \pm S.D. from three independent experiments 
a
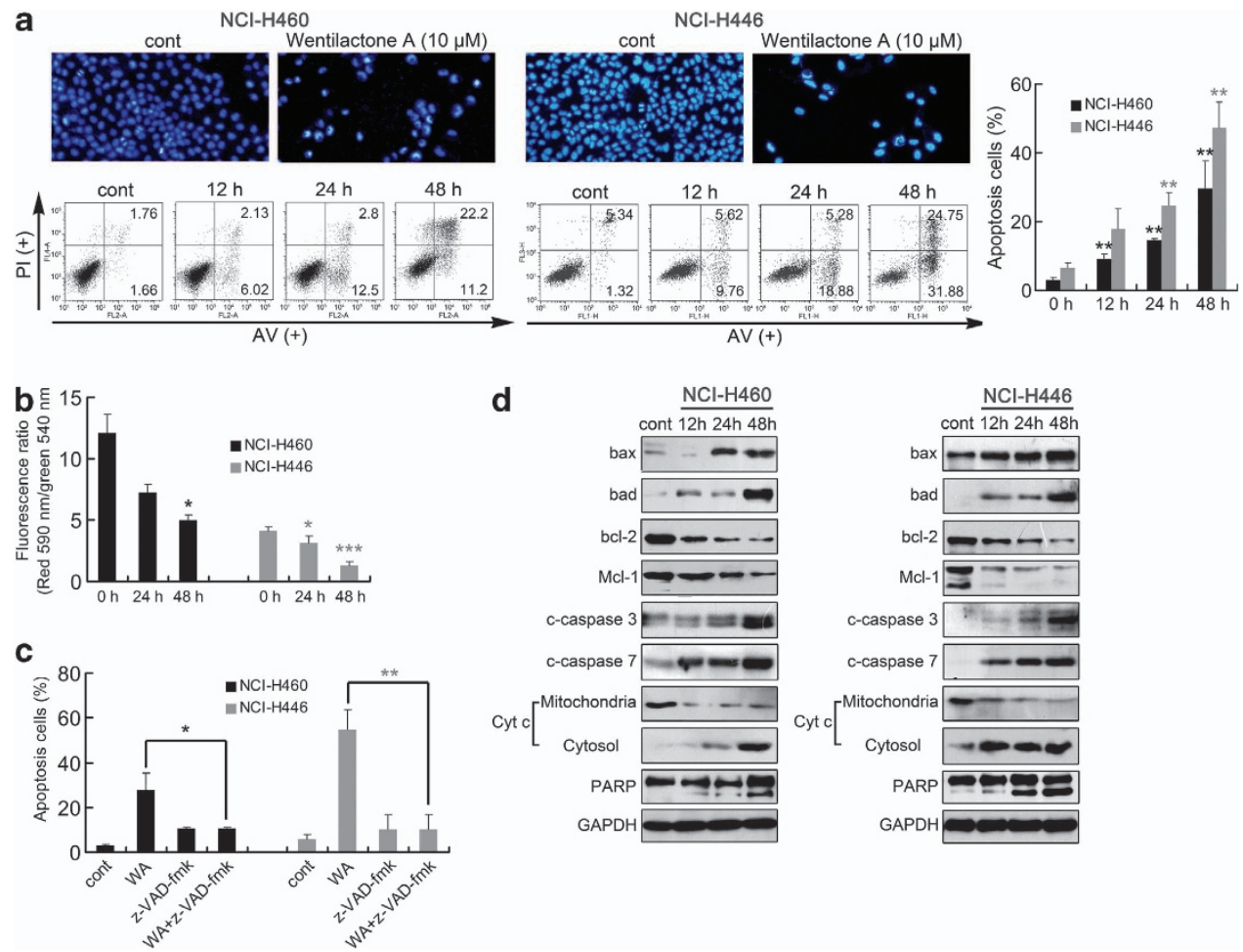

Figure 2 WA triggers mitochondrial-related apoptosis in NCI-H460 and NCI-H446 cells. (a) WA-induced morphological changes as indicated by DAPI staining. Representative photomicrographs of control and $48 \mathrm{~h} 10 \mu \mathrm{M}$ WA treatment groups are showed. Apoptosis in NCI-H460 and NCl-H446 cells was assessed after $12-48 \mathrm{~h}$ of treatment with $10 \mu \mathrm{M}$ WA by Annexin V-FITC/PI binding and measured by flow-cytometry analysis. Numbers indicate the percentage of cells in each quadrant. ${ }^{*} P<0.01$ versus the drug-untreated group. (b) The mitochondrial membrane potential was measured using JC-1 by flow cytometry. Decrease in the ratio of the green fluorescence (FITC) to the red fluorescence (PE) indicates loss of $\Delta \Psi \mathrm{m}$. (c) NCl-H460 and NCl-H446 cells were treated with $20 \mu \mathrm{M}$ z-VAD-fmk, a caspase inhibitor, for $1 \mathrm{~h}$ before treatment with $10 \mu \mathrm{M}$ WA for $48 \mathrm{~h}$. Apoptosis was assessed by flow cytometry as mentioned above. ${ }^{*} P<0.05,{ }^{* *} P<0.01$. (d) Western blot of cells analyzed for bax, bad, bcl-2, Mcl-1, cleaved caspase-3/7, PARP, cytochrome $c$ in cytosol and mitochondria after treatment with $10 \mu \mathrm{M}$ WA for the indicated time periods. Results are representative of three separate experiments. GPDH is shown as protein-loading control

PARP was also observed (Figure 2d), indicating activation of the intrinsic apoptosis pathway in WA-induced cell death.

WA induces G2/M arrest. In order to examine whether cellcycle disturbance is responsible for WA-mediated cell growth inhibition, cell-cycle distribution and related checkpoint factors were studied. Cells were treated with $10 \mu \mathrm{M}$ WA for 24 and $48 \mathrm{~h}$, respectively. The results showed that WAtreated cells accumulated progressively in the G2/M phase (Figure 3a). Compared with the control, treatment with WA for $48 \mathrm{~h}$ resulted in an increased proportion of $\mathrm{G} 2 / \mathrm{M}$ phase in $\mathrm{NCl}-\mathrm{H} 460$ cells from $10.44 \%$ (control) to $29.34 \%$ (48h, WA) and from $5.43 \%$ (control) to $13.16 \%$ (48 h, WA) in NCl-H446 cells, about a 3-fold and 2.5-fold increase, respectively. Besides, WA treatment resulted in a time-dependent decrease in the protein expression of cyclin B1, cdc2, $\mathrm{p}-\mathrm{cdc} 2$, cdc25C and p-cdc25C (Figure 3b). Contrary to the expectation, protein levels of p-cdc25C (Ser216) and p-cdc2 (Tyr15) were decreased after WA treatment, which might be caused by the drastic decrease in the total expression of cdc25C and cdc2. All the above suggest that G2/M phase arrest also accounts for the antiproliferative effect of WA in both cells and more significantly in $\mathrm{NCl}-\mathrm{H} 460$ cells.

ERK and p53 regulate WA-induced apoptosis and G2/M arrest. Mitogen-activated protein kinase (MAPK) signaling cascades have been proved to have essential roles in the regulation of a wide variety of cellular processes, including cell growth, migration, proliferation, differentiation, development, apoptosis and cell growth arrest. ${ }^{16}$ To further investigate the possible mechanism of WA, the activations of ERK, JNK and p38 MAP kinases were determined in both cell lines. Immunoblot showed that the phosphorylations of ERK, p38 and JNK were significantly increased after WA treatment (Figure 4a), and pre-treatment with $20 \mu \mathrm{M}$ PD98059, SB203580 or SP600125 almost completely blocked phosphorylation of ERK, p38 or JNK (Figure 4b). However, only ERK inhibitor PD98059 significantly inhibited WA-induced apoptosis and G2/M arrest, and brought apoptosis-related and G2/M regulatory proteins to normal levels. There was no significant difference between the WAtreatment group and the JNK or p38 inhibitor pre-treatment group (Figure 4c). Considering that p53, which is a critical determinant in controlling both cell-cycle arrest and apoptosis, ${ }^{17,18}$ usually has crosstalk with MAPKs, ${ }^{19}$ and the downstream regulator p21 is probably involved in G2/M arrest through the p53-dependent pathway, ${ }^{20}$ we detected p53 and p21 protein levels using western blot analysis. The data showed that WA treatment caused a marked timedependent increase in the phosphorylation status of p53 and in the level of p21 protein (Figure 4d). Then the role of p53 in WA-induced apoptosis and G2/M arrest was studied. Cells 
a

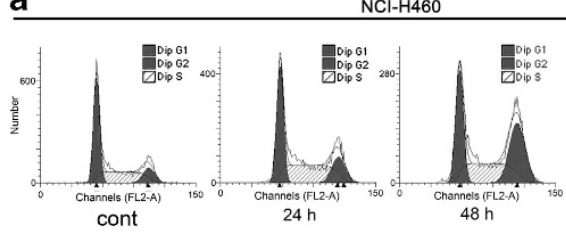

$\mathrm{NCl}-\mathrm{H} 446$

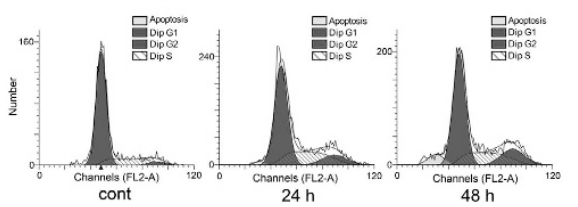

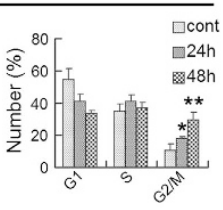

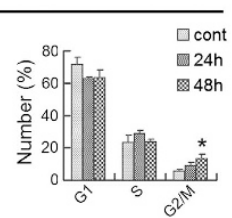

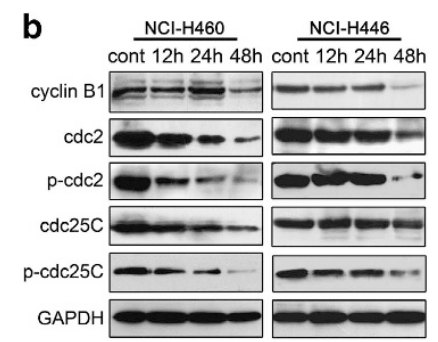

Figure 3 WA induces cell-cycle arrest in NCl-H460 and NCl-H446 cells. (a) Cells were treated with or without $10 \mu \mathrm{M}$ WA for the indicated time periods and then the cellcycle distribution was measured using flow cytometry. The percentage of cells in each population was shown as mean \pm S.D. from three independent experiments. ${ }^{*} P<0.05$, ${ }^{* *} P<0.01$. (b) Western blot analysis of G2/M transition-related proteins after WA treatment

a

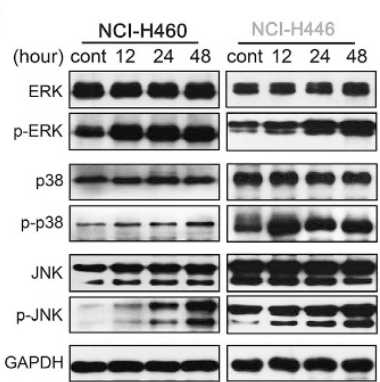

C

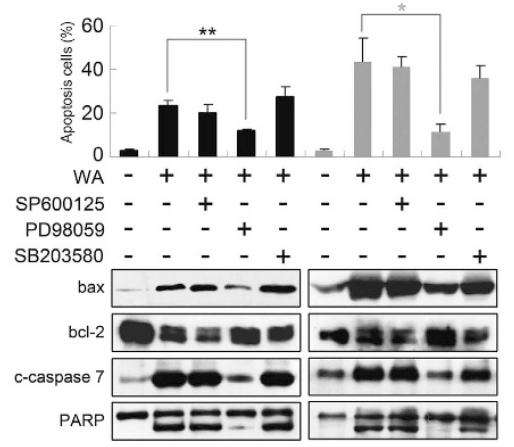

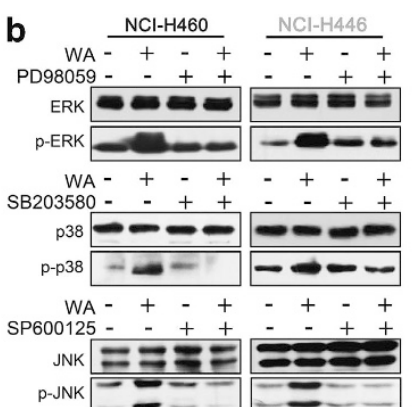

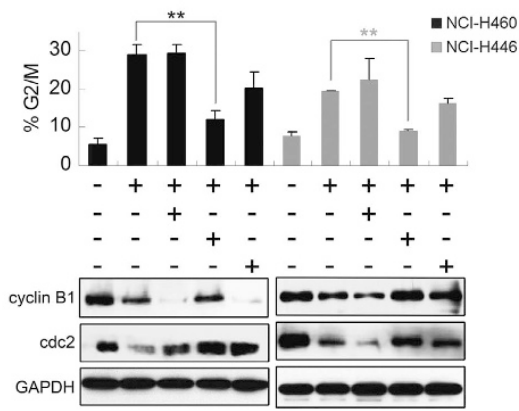

d

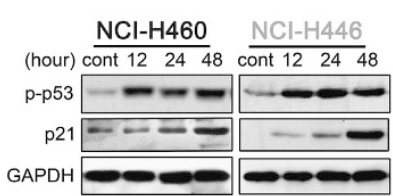

e

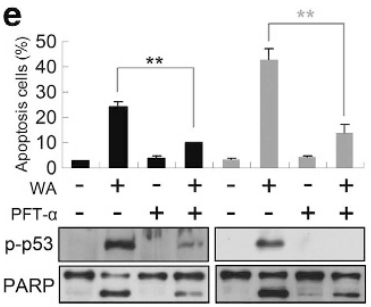

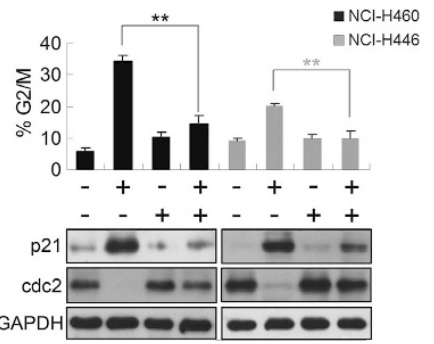

Figure 4 ERK and p53 regulate WA-induced apoptosis and G2/M arrest. (a) Cells were treated with $10 \mu \mathrm{M}$ WA for various incubation times, total and phosphorylated MAPK members (JNK, p38, ERK) were detected using immunoblot assay. (b) Cells were pre-treated with $20 \mu \mathrm{M}$ MEK inhibitor (PD98059), JNK inhibitor (SP600125) or p38 inhibitor (SB203580) followed by treatment with or without $10 \mu \mathrm{M}$ WA for $48 \mathrm{~h}$. Total and activation forms of ERK, JNK or p38 were evaluated by western blotting; (c) Cells were pre-treated with the indicated inhibitor for $1 \mathrm{~h}$, then treated with $10 \mu \mathrm{M}$ WA for $48 \mathrm{~h}$ and analyzed for apoptosis, cell-cycle analysis and expression of bax, bcl-2, cleaved caspase-7, PARP, cyclin B1 and cdc2. (d) p-p53 (Ser 15) and p21 protein levels were detected after WA treatment. (e) Cells were incubated for $1 \mathrm{~h}$ in the presence or absence of PFT- $\alpha(20 \mu \mathrm{M})$ and then $10 \mu \mathrm{M}$ WA was added followed by incubation for an additional $48 \mathrm{~h}$. The induction of apoptosis and cell-cycle distribution were determined by flow cytometry. Apoptosis and G2/M checkpoint-related proteins were detected by western blot. Values are means \pm S.D. from three independent experiments. ${ }^{*} P<0.05$, ${ }^{* *} P<0.01$ 
were pre-treated with $20 \mu \mathrm{M}$ p53 inhibitor Pifithrin- $\alpha$ (PFT- $\alpha$ ) for $1 \mathrm{~h}$ before incubating WA for a further $48 \mathrm{~h}$. As shown in Figure $4 \mathrm{e}$, pre-treatment with $\mathrm{PFT}-\alpha$ prevented the WAinduced apoptosis and reduced the accumulation of p21 and G2/M phase cells, suggesting that WA initiated apoptosis and G2/M phase arrest via p53-p21 participation and activation. WA treatment also resulted in a marked timedependent reactive oxygen species (ROS) accumulation (see Supplementary Material). ROS is known to be a mediator of MAPKs, SAPKs, and so on. ${ }^{21}$ Numerous investigations have documented that following exposure to cytotoxic drugs, excessive production of ROS in cells usually induced the loss of cell function and apoptosis/necrosis. ${ }^{22-24}$ However, in this study, ROS is not the major mediator of WAinduced cell death and growth inhibition in human lung carcinoma cells but a 'post-mitochondrial' event and fails to regulate MAPK signals (Supplementary Figure S1). ${ }^{25,26}$

WA induces cell-cycle arrest and apoptosis through a Ras/Raf/ERK/p53-p21-dependent pathway. As described above, it is essential to check whether Ras, a common activator of the ERK signaling pathway, is involved in WA's toxic effect on $\mathrm{NCl}-\mathrm{H} 460$ and $\mathrm{NCl}-\mathrm{H} 446$ cells. The activation of Ras was tested by precipitating the GTP-bound forms of Ras using the Ras-binding domain (RBD) of Raf-1 as an activation-specific probe. ${ }^{27}$ As observed in Figure $5 a$, WA treatment did not alter the expression level of total Ras; KRas-GTP of NCl-H446 cells and NRas-GTP in both cells were almost not observed; and because of an activating mutation of $\mathrm{KRas}(\mathrm{Q} 61 \mathrm{H})$ in $\mathrm{NCl}-\mathrm{H} 460$ cells, numerous activated forms of KRas were detected; however, no obvious changes of KRas-GTP were observed after the WA treatment. WA only induced the activation of HRas in both cells, and the phospho-c-Raf ( $\mathrm{p}-\mathrm{c}-\mathrm{Raf}$ ) presented consistent changes with HRas-GTP (Figure 5a).

To investigate whether Ras is responsible for WAinduced cell death or growth inhibition, we used small interfering RNA (siRNA) to knock down HRas, and observed that WA-induced apoptosis and G2/M arrest in both cells were significantly abolished (Figure 5b).
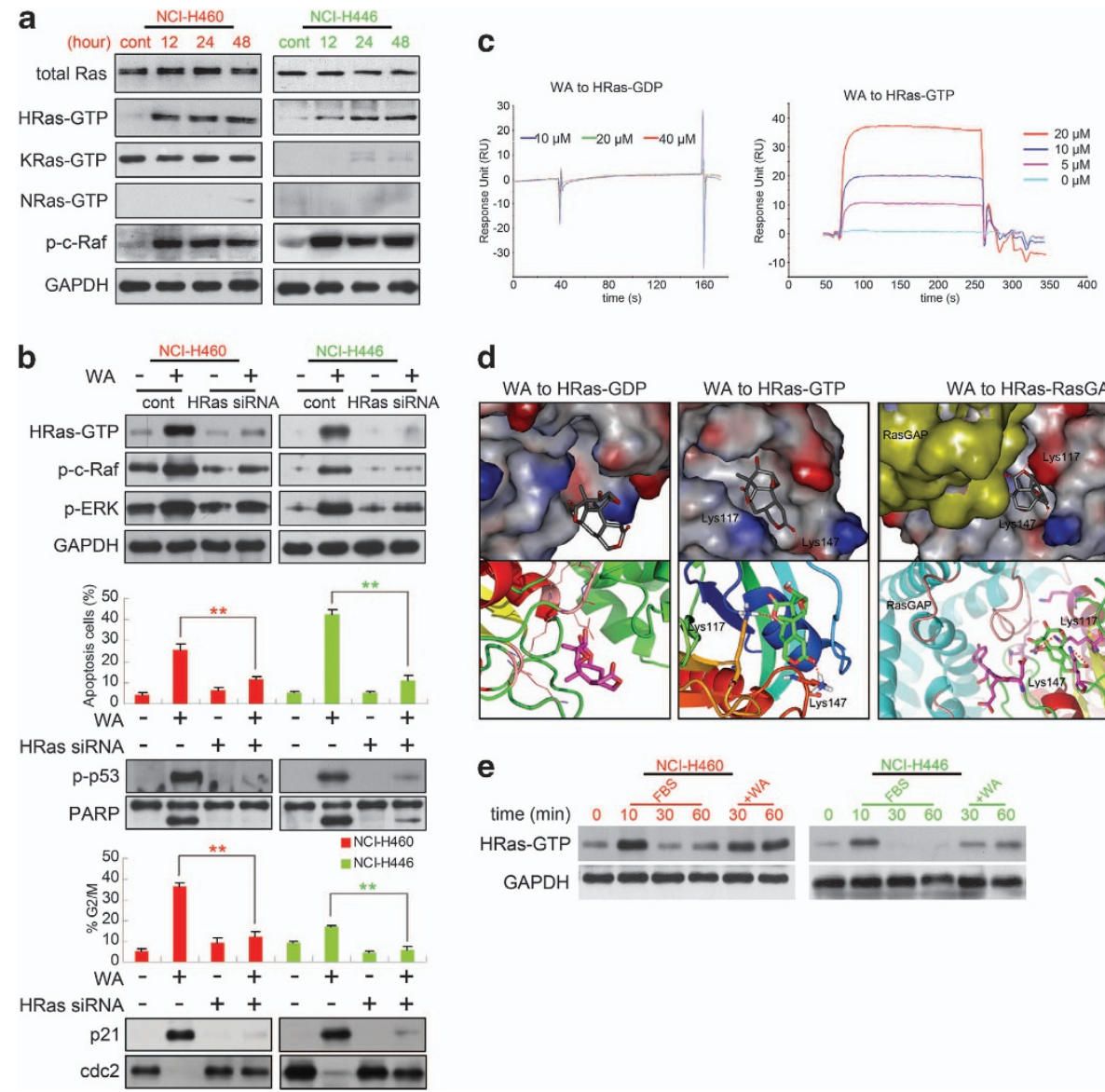

d
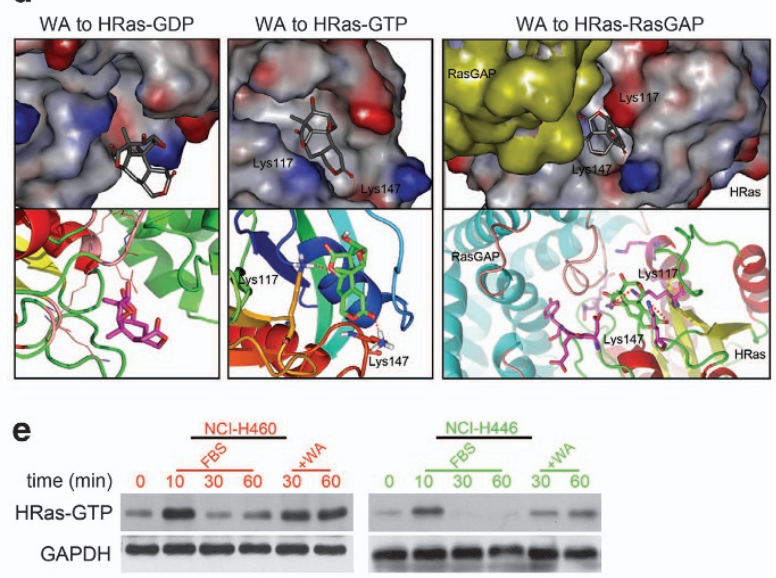

Figure 5 WA targets HRas to activate the Ras/Raf/ERK/p53-p21 pathway. (a) Total Ras, HRas-GTP, KRas-GTP, NRas-GTP and p-c-Raf (Ser338) protein levels were increased in both cells after $10 \mu \mathrm{M}$ WA treatment. (b) Cells transfected with HRas siRNA or not were treated with or without $10 \mu \mathrm{M}$ WA for $48 \mathrm{~h}$, then cells were harvested for western blot assay against HRas-GTP, p-c-Raf, p-ERK. Apoptosis, cell-cycle analysis and related-proteins were also detected at $48 \mathrm{~h}$. Values were means \pm S.D. of three independent experiments. ${ }^{*} P<0.05,{ }^{* *} P<0.01$ versus control groups. (c) Binding affinity of WA to the HRas-GDP and HRas-GTP proteins determined by SPR. (d) $3 D$ structure of interaction between WA and HRas-GDP (left), HRas-GTP (middle) or HRas-RasGAP (right) in detail. WA is represented by the stick model. Hydrogen bond was signed in red. (e) Starved cells were stimulated with $10 \%$ FBS or incubated with WA after 10 min FBS stimulation for the indicated time points. HRas-GTP levels were monitored using immunoblot assay 
In addition, HRas siRNA brought p-c-Raf, p-ERK, p-p53, p21, PARP and cdc2 expressions to normal levels (Figure 5b).

The results achieved above led us to consider whether HRas is the potent target of WA. Thus, surface plasmon resonance (SPR) biosensor analysis was used to test direct binding of WA to HRas-GTP/GDP protein, and the binding affinity of WA to the proteins was reflected by response unit $(R U)$ values. The binding between WA and HRas-GDP showed no response (Figure $5 \mathrm{c}$ left), while WA binding to HRas-GTP presented a significant and dose-dependent increase in response unit with $K_{\mathrm{D}}=15.7 \mu \mathrm{M}$ (Figure $5 \mathrm{c}$ right), indicating that WA may have a specific binding affinity toward Ras-GTP. But how does this binding induce HRas-GTP accumulation? We further employed molecular docking to investigate WA-HRas interaction at the atomic level. The 3D structural model of Ras-GTP was obtained from the Protein Data Bank (PDB ID: 4DLR). As shown in Figure 5d, WA located at the GTP-binding site through hydroxyl oxygen atoms forming two O-H hydrogen bonds with the HRas-GTP residues Lys 117 and Lys147, and the binding energy was - $145.53 \mathrm{kcal} / \mathrm{mol}$ (middle); as for HRas-GDP (PDB ID: 3KUD), WA could also enter the GDP-bingding cavity, but no hydrogen bonds could be formed (left). These docking results confirmed the former SPR analysis. In addition, Lys117 and Lys147 were just the two residues on the interface binding pocket of HRas with Ras-specific GTPase activating proteins (RasGAPs, or GAPs), and GAPs, which supply additional catalytic residues ('arginine finger') such that a water molecule is optimally positioned for a nucleophilic attack on the gamma phosphate of GTP, hydrolyze a bound GTP molecule into GDP. ${ }^{28}$ Therefore, referring to the HRas-RasGAP interaction (PDB ID: 1WQ1, Figure 5d right), WA forming hydrogen bonds with Lys117 and Lys147 residues might interfere with RasGAP to convert Ras-GTP into GDP-bound form, which might induce Ras-GTP accumulation. Finally, this model was confirmed by using fetal bovine serum (FBS) stimulation. When cells were serum starved for $24 \mathrm{~h}$ and then stimulated with FBS, HRas was rapidly activated; HRas activation reached a maximum after $10 \mathrm{~min}$ (Figure $5 \mathrm{e}$ lane 2 ) and returned close to the pre-stimulation level within $30 \mathrm{~min}$ (Figure 5 e and lane 3). When WA was added after $10 \mathrm{~min}$ of FBS stimulation, we observed that HRas-GTP no longer returned to pre-stimulation level and remained in continuous active form (Figure 5e, lanes 5 and 6). This in vitro model further confirmed the docking results that WA might enter the HRas-RasGAP complex to interfere with the interaction of HRas-GTP and RasGAP.

Collectively, these results suggest that WA led HRas-GTP accumulation to excessively activate the Ras/Raf/ERK/p53p21 pathway, which induced apoptosis and G2/M arrest of human lung carcinoma cells.

WA inhibits tumor xenograft growth. The injected carcinoma cells grew into palpable tumors in the nude mice within 4 days (Figure 6a). Cyclophosphamide-treated mice $(20 \mathrm{mg} / \mathrm{kg}$ per day) or cisplatin-treated mice $(2.5 \mathrm{mg} / \mathrm{kg})$ were used as positive control to assess the effect and toxicity of WA. In mice treated with vehicle (1\% DMSO in PBS) only, the tumors grew exponentially. However, the tumor growth in mice treated with WA $(2.5,5$, or $10 \mathrm{mg} / \mathrm{kg}$ per day) was dose-dependently slowed. Tumor volume was significantly reduced during WA treatment (Figures $6 \mathrm{c}$ and $\mathrm{cc}$ ). The inhibitory rates at the 20th day of the $2.5,5$ and $10 \mathrm{mg} / \mathrm{kg}$ WA treatment groups of $\mathrm{NCl}-\mathrm{H} 460$ xenograft-bearing mice were $48.71 \%, 85.11 \%$ and $95.58 \%$, respectively (Figure $6 \mathrm{~b}$ ); as for the $\mathrm{NCl}-\mathrm{H} 446$ xenograft-bearing mice, inhibitory rates were $33.78 \%, 80.84 \%$ and $87.12 \%$, respectively (Figure 6bb). It should be noted that compared with the more effective Cisplatin-positive control of the two models (inhibition rates of $88.76 \%$ and $91.90 \%$, respectively), $10 \mathrm{mg} / \mathrm{kg}$ WA treatment showed equivalent effect and weight gain during the course of therapy; however, significant weight loss was found in the cisplatin-treated animals (Figures $6 \mathrm{~d}$ and $\mathrm{dd}$ ).

In addition, immunohistochemical staining showed significant increase of active caspase-3 and decrease of cdc2 expression in tumors of the WA-treated mice (Figures $6 f$ and ff), which was in accordance with the cell death and growth inhibition results obtained from the in vitro analyses. Increase in p-ERK and HRas-GTP (Figure $6 f$ and ff) was also observed, indicating the same cell signaling mechanism as that in vitro. Furthermore, protein expression account was similar between the $10 \mathrm{mg} / \mathrm{kg}$ WA-treatment group and $2.5 \mathrm{mg} / \mathrm{kg}$ cisplatin group.

\section{Discussion}

In our study, WA significantly suppressed tumor cell growth in vivo and in vitro. It induced G2/M phase arrest and mitochondrial-related apoptosis via the Ras/Raf/ERK/p53p21 signaling pathway (Figure 7).

Tumor suppressor p53 is a short half-life regulator. The function of p53 is achieved by increased expression at the transcriptional level and post-translational stabilization to escape ubiquitin-dependent degradation. ${ }^{29,30}$ Phosphorylation of p53 at serine 15 and 46 sites is the main posttranslational modification that is regulated by several different protein kinases, including ataxia-telangiectasia-mutated kinase $^{31}$ and MAPK. ${ }^{32}$ The way of phosphorylation depends on the types of cells and extracellular stimuli. We reported here that WA caused a significant time-dependent phosphorylation of p53 at serine 15 in both lung carcinoma cells. The increased phosphorylation and accumulation of p53 may lead to mitochondrial apoptosis by upregulating and derepressing proapoptotic members of the bcl-2 family, such as bax, bak, bad, bid, puma and so on, while on the other hand downregulating and repressing antiapoptotic members, such as bcl-2, bcl-xl, Mcl-1 and so on. ${ }^{33-39}$ Therefore, WA-induced phosphorylation and accumulation of p53 should be responsible for decreased bcl-2/Mcl-1, and increased bax/bad. In addition, p53 utilizes and increases the transcription of its downstream molecular p21 to modulate cdc2-the cyclindependent kinase required to enter mitosis. ${ }^{18}$ P21 acts not only as one of the transcription targets of p53, but also as an inhibitor of cell-cycle progression through the G2/M checkpoint. ${ }^{17,20}$ When phosphorylation of p53 was blocked by PFT$\alpha$, apoptosis and cell G2/M arrest were almost abolished, accompanied by recovery of p21 and cdc2 in both cell lines. Therefore, we conclude WA-induced apoptosis and G2 phase 


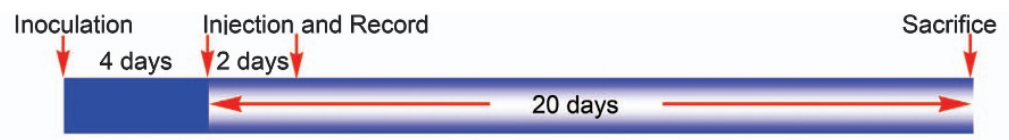

b

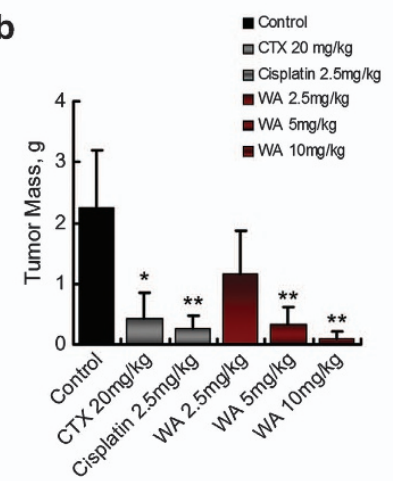

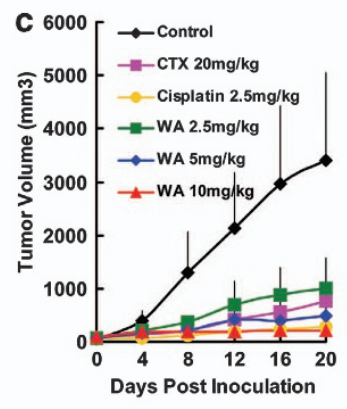

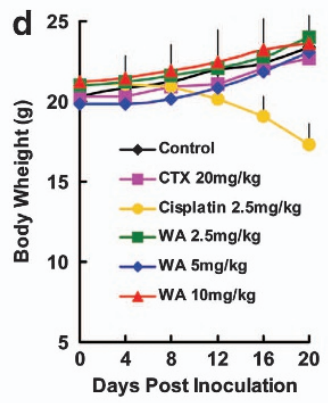

e
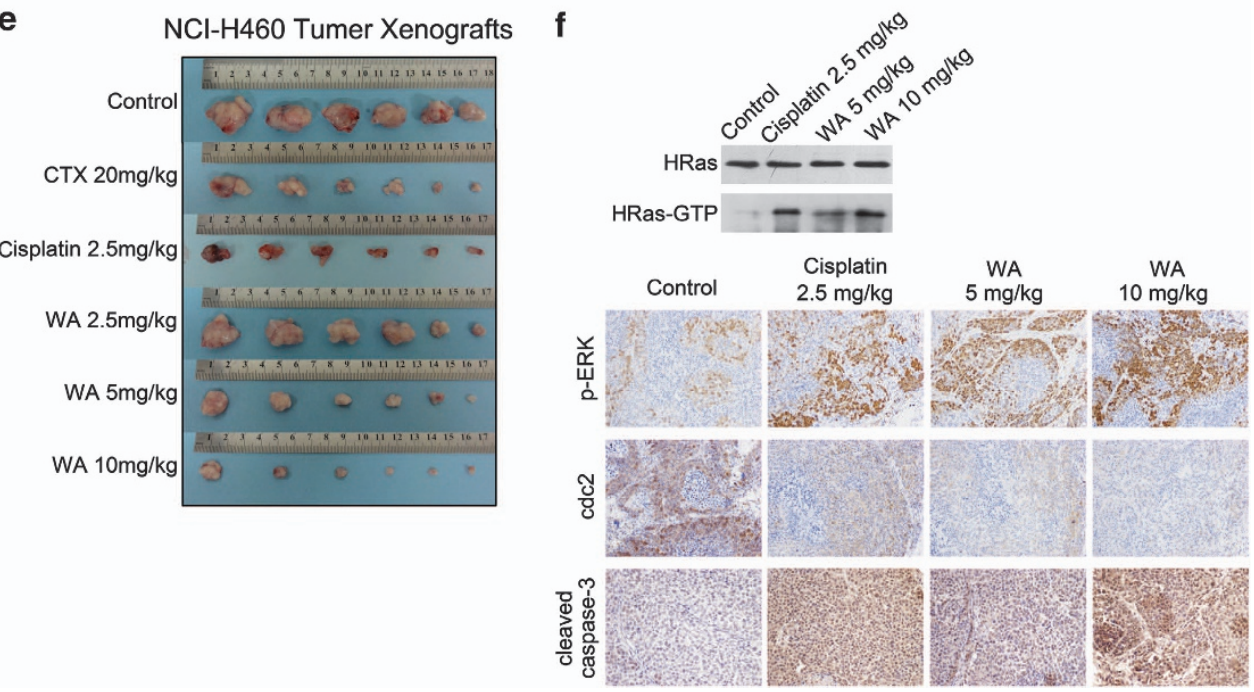

Figure 6 Effect of WA on tumor growth in xenograft models. Mice were treated with vehicle (1\% DMSO) or drugs according to the protocol in panel (a); (b-f) and (bb-ff) are the results from $\mathrm{NCl}-\mathrm{H} 460$ xenograft bearing mice and $\mathrm{NCl}-\mathrm{H} 446$ xenograft bearing mice, respectively. (b and bb) Average tumor mass at sacrifice. ${ }^{*} P<0.05$, ${ }^{*} P<0.01$ versus control group. (c and cc) Transplant tumor volume after the injection. (d and dd) Body weight of nude mice. (e and ee) Tumor image from various treatment groups. ( $f$ and ff) Western blot assay for HRas, HRas-GTP and representative photomicrographs of xenograft tumor sections for IHC analysis for $p$-ERK, cdc2 and active caspase-3 expression $(\times 200)$. Significantly increased HRas-GTP, p-ERK, active caspase-3 and decreased cdc2 expressions were observed in the WA-treated tumors compared with the vehicle control groups

arrest in human $\mathrm{NCl}-\mathrm{H} 460$ and $\mathrm{NCl}-\mathrm{H} 446$ lung carcinoma cells is mediated by p53-p21 stabilization.

The diverse, even opposing, effects of ERK on cell behavior have been reviewed in recent years, ${ }^{40}$ and ERK usually has crosstalk with p53 signaling in aspects of cell autophagy and apoptosis, ${ }^{41}$ whereas Ras protein is best known for its ability to serve as a molecular switch regulating cell growth, differentiation and survival. Gene mutations that result in expression of constitutively active forms of Ras have been linked to oncogenesis. ${ }^{42}$ However, considerable evidence has gradually accumulated to support a paradoxical role for Ras proteins in initiation of cell death pathways. ${ }^{43}$ Here we observed that WA induced the activation of HRas in both cells, and knockdown HRas with siRNA not only suppressed the WA-induced G2/M arrest and apoptosis, but also brought p-c-Raf, p-ERK, p-p53 and p21 to normal level, suggesting that Ras mediated Raf/ERK/p53/p21 signaling and active Ras sent death signals to cells by WA treatment. In light of the balance and interplay of multiple signaling networks involved in various signaling contexts of different cell type and stimuli, it is not surprising that Ras/ERK regulation is complex. But we can simply explain the dual, even opposing, functions of the proteins by the notion that: ultimate growth or death is based on signal intensity and duration. It is just like there is a baseline under which cell growth capacity is in proportion to the signal intensity; if sustained and strengthened signal accumulates to overcome the baseline, growth is inversely related to signal intensity and finally converts to death. ${ }^{21}$ Thus, under growth condition or other relatively weak stimuli toward Ras/ERK, elevated activation of Ras/ERK confers a growth advantage to tumor cells. However, exposure of these cells to damaging agents that induce prolonged substantial increase of active Ras/ERK level results in initiation of apoptosis. As in the case of our study, Ras was constantly activated. The activation 

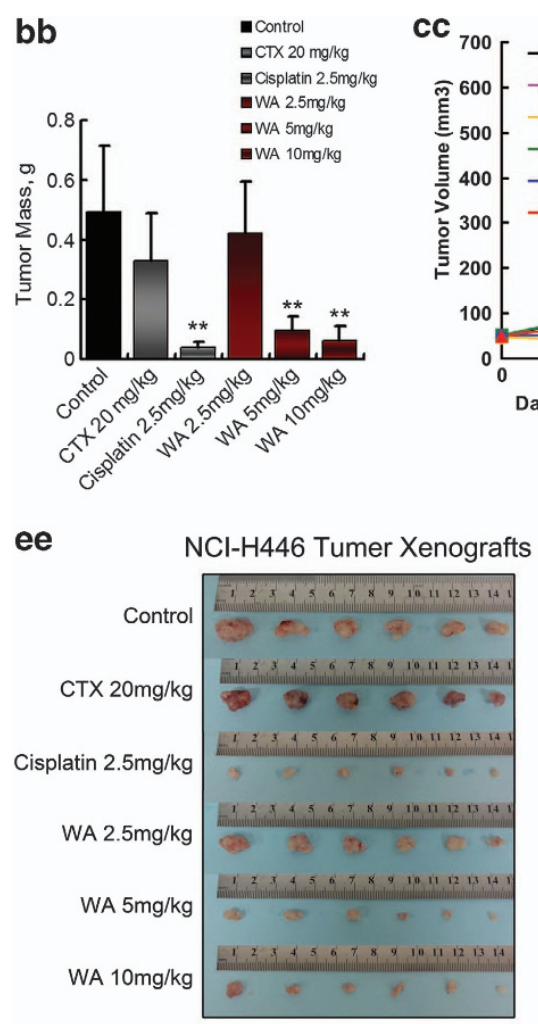
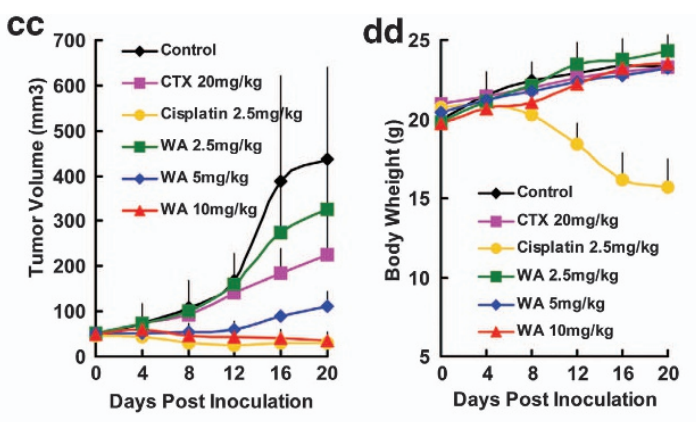

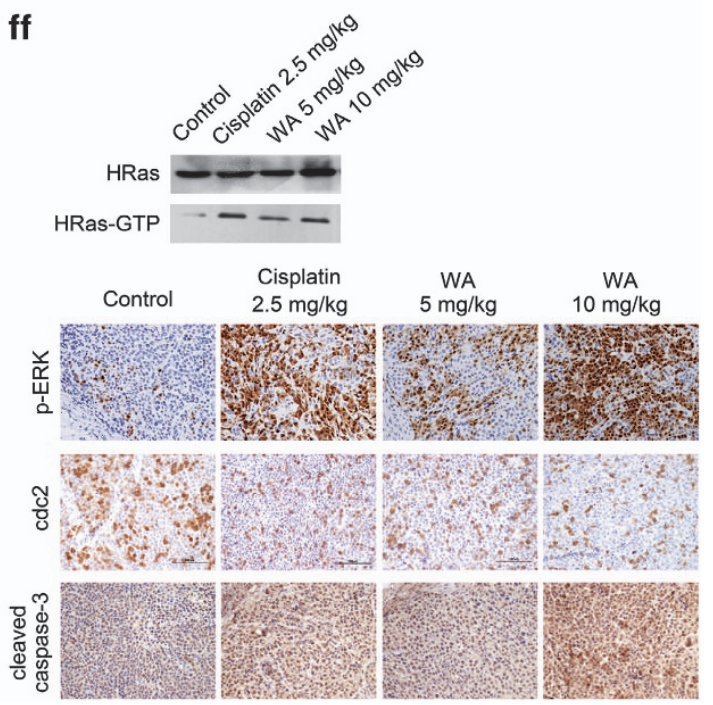

Figure 6 (Continued)

prolonged to $48 \mathrm{~h}$ at least, which in turn created and sent a damage signal to cells. In addition, compared to the $I C_{50}$ (5.56 \pm 0.89 and $1.90 \pm 1.30 \mu \mathrm{M}$, respectively) and apoptosis rate $(29.65 \pm 7.91 \%$ and $47.34 \pm 7.36 \%$ apoptosis at $48 \mathrm{~h}$, respectively) of the two lung carcinoma cells, we noticed that $\mathrm{NCl}-\mathrm{H} 446$ presented more sensitivity to WA treatment than $\mathrm{NCl}-\mathrm{H} 460$ cells, which is probably because $\mathrm{NCl}-\mathrm{H} 460$ cells have an activating mutation in KRas $(\mathrm{Q} 61 \mathrm{H})$. The mutation leads to an elevated basal level/activity of Ras/Raf/ERK signaling, and higher baseline to overcome.

It is well accepted that small-molecule drugs generally exert their therapeutic functions by binding to the cavities of proteins to influence their biological activities. ${ }^{44}$ In our study, it seemed only HRas (one of the Ras isoforms) was selectively chosen to act as the mediator of WA-induced apoptosis and G2/M arrest. Therefore, whether WA directly binded to HRas needs to be clarified. SPR analysis showed that WA might have a specific binding affinity toward HRas-GTP. Molecular docking further indicated WA could insert HRas-GTP, forming hydrogen bonds with HRas-GTP at Lys117 and Lys147 residues, which interfered with the GAP catalytic activity and then induced Ras-GTP accumulation. We know that GAPs and guanine-nucleotide-exchange factors bind to Ras proteins and regulate their activity by modulating guanine nucleotide cycling. Guanine-nucleotide-exchange factors activate Ras by promoting exchange of GDP for GTP. Conversely, GAPs have the opposite function and lead to inactivation of Ras by facilitating hydrolysis of GTP to GDP. ${ }^{45}$ As shown in Figure 5e, after 10\% FBS stimulation, starved cells could elevate HRas-GTP levels rapidly through guanine-nucleotideexchange factor regulation, followed by GAPs facilitating hydrolysis of GTP to GDP in a short time ${ }^{46,47}$ Addition of WA inhibited the return of HRas-GTP to pre-stimulation level and maintained HRas-GTP in continuous active form, which suggested that WA weakened or even eliminated the catalytic activity of GAP. This model also confirmed the molecular docking results.

In vivo, WA treatment significantly reduced tumor growth in the two models. $10 \mathrm{mg} / \mathrm{kg}$ WA treatment showed equivalent effect with $2.5 \mathrm{mg} / \mathrm{kg}$ Cisplatin. It is well known that cisplatin is a chemotherapeutic agent used in the treatment of a wide range of human malignancies, including NSCLC and SCLC. Though Cisplatin combination chemotherapy is the cornerstone of treatment of many cancers, serious adverse effects offset the productivity of treatment and renders the chemotherapy unsustainable. ${ }^{48,49}$ As we observed in this study, significant weight loss was found in the cisplatin-treated animals. In contrast, the weight gain of WA-treated mice indicated the potential clinical benefit of WA in reduced adverse toxicity and the feasibility for upward adjustment of 


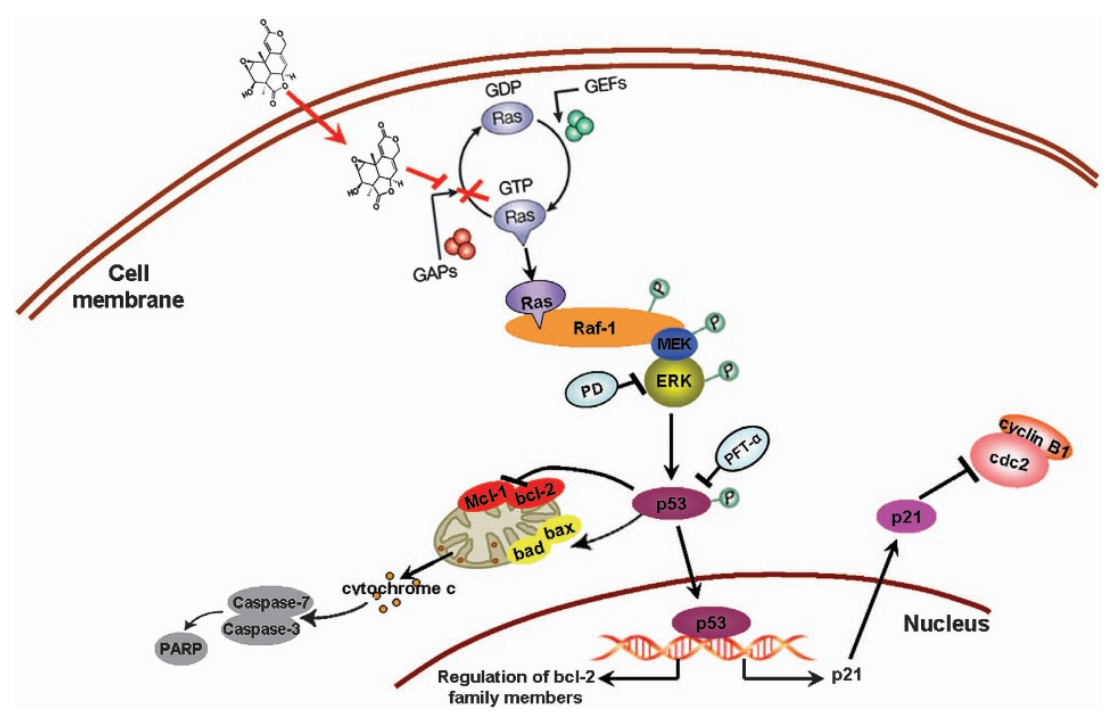

Figure 7 Overview of pathways for WA-induced apoptosis and cell-cycle arrest in NCl-H460 and NCl-H446 cells

dosage for improved treatment outcomes compared with cisplatin.

Taken together, our results demonstrate that WA directly targets HRas-GTP and excessively activates the Ras/Raf/ ERK pathway, which initiates apoptosis and G2/M phase arrest via p53-p21 participation and stabilization during human lung carcinoma cell proliferation (Figure 7). Moreover, administration of WA significantly suppressed the growth of lung carcinama xenograft by inducing apoptosis and G2/M arrest via the same cell signaling pathway in the tumor cells. Our studies thus provide a rationale for the development of WA as a chemotherapeutic agent against NSCLC/SCLC in the clinical setting.

\section{Materials and Methods}

Reagents. DMEM, RPMI 1640 medium, FBS, trypsin-EDTA, penicillin and streptomycin were purchased from Biowest (Maine et Loire, France). Annexin V-FITC/PI apoptosis detection kit, DAPI, JC-1 detection kit and cell-cycle detection kit were provided by Nanjing KeyGen Biotech Co Ltd. (Nanjing, China). GAPDH was obtained from Tianjin Sungene Biotech (Tianjin, China). Rabbit polyclonal anti-active caspase-3 antibody (AB3623) for immunohistochemistry was provided by Millipore (Chemicon International, Temecula, CA, USA). Anti-GTPase HRas antibody (ab16881) was from Abcam (Hong Kong, China); K-Ras, N-Ras antibodies and H-Ras siRNA were from Santa Cruz Biotechnology Inc. (Santa Cruz, CA, USA). All the other antibodies were purchased from Cell Signaling Technology (Beverly, MA, USA). Ras activity was assessed using the Ras activation assay kit from Upstate Biotechnology (Temecula, CA, USA). $z$-VAD-fmk, PD98059, SP600125, SB203580 and PFT- $\alpha$ were bought from Beyotime Institute of Biotechnology (Nantong, Jiangsu, China). Recombinant human HRas-GDP (purify $>90 \%$ ) was purchased from Cusabio Biotech Co. Ltd (Wuhan, China). Human recombinant protein Ras-GTP (purify $\geq 90 \%$ ) was obtained from Abcam (Hong Kong, China).

Chemical preparation and cell culture. WA, isolated from a marinederived endophytic fungus $A$. wentii EN-48, ${ }^{13}$ was dissolved in $100 \%$ DMSO and stored at $-20^{\circ} \mathrm{C}$, then diluted with cell culture media before using. The final DMSO concentration did not exceed $0.1 \%$. Human large cell lung carcinoma cell line $\mathrm{NCl}-\mathrm{H} 460$, small-cell lung cancer cell line $\mathrm{NCl}-\mathrm{H} 446$ and human umbilical vein endothelial cell line HUVEC were obtained from the cell bank of the Shanghai Institute of Cell Biology (Shanghai, China). NCl-H460 and $\mathrm{NCl}-\mathrm{H} 446$ cells were cultured in RPMI-1640 medium; HUVECs were maintained in DMEM. All cells were supplemented with 10\% FBS and antibiotics (100 $\mu \mathrm{g} / \mathrm{ml}$ streptomycin and $100 \mathrm{U} / \mathrm{ml}$ penicillin) in a humidified $5 \%$ $\mathrm{CO}_{2}$ incubator at $37^{\circ} \mathrm{C}$.

Cell viability assay. Cells were seeded into 96 -well plates at $4 \times 10^{4}$ cells $/ \mathrm{ml}$, incubated for $24 \mathrm{~h}$, and then treated with the indicated concentrations of WA $(0,2.5,5,10,20,40$ and $80 \mu \mathrm{M})$ for 24 and $48 \mathrm{~h}$. Cell viability was determined using the MTT assay.

Clonogenic assay. $\mathrm{NCl}-\mathrm{H} 460$ cells and $\mathrm{NCl}-\mathrm{H} 446$ cells (500 cells/well) were seeded in six-well plates and cultured for $24 \mathrm{~h}$, followed by various concentrations of WA treatment $(0,5,10,20$ and $40 \mu \mathrm{M})$ for 10-14 days. After washing with PBS, colonies were fixed in methanol and stained with trypan blue.

DAPI staining. Cells were fixed with $1 \%$ paraformaldehyde for 30 min at room temperature. After washing with PBS, $300 \mathrm{nM}$ DAPI was added to the fixed cells for $5 \mathrm{~min}$ and examined by fluorescence microscopy. Apoptotic cells were identified by condensation and fragmentation of nuclei.

Cell apoptosis assay. Cell apoptosis was determined by Annexin V-FITC/PI assay. After treatment, cells were collected and resuspended with $500 \mu \mathrm{l}$ binding buffer at a concentration of $10^{6} / \mathrm{ml}$ cells. After adding $5 \mu \mathrm{l}$ Annexin V-FITC, cells were mixed and incubated at room temperature in the dark for 5-15 min. To the samples was added $5 \mu \mathrm{lPI}$ and resuspended before analysis with a FACScalibur flow cytometer. Results were calculated by using the CellQuest software.

Mitochondrial membrane potential $(\Delta \Psi \mathrm{m})$ assay. Change of mitochondrial membrane potential $(\Delta \Psi \mathrm{m})$ was examined by fluorescent lipophilic cationic probe $\mathrm{JC}$-1. Following treatment with $10 \mu \mathrm{M}$ WA for the indicated time points, cells were stained with JC-1. Fluorescence was monitored at wavelengths of 490 (excitation)/540 nm (emission) and 540 (excitation)/590 nm (emission) pairs. Changes in the ratio between 590 (red) and $540 \mathrm{~nm}$ (green) fluorescence intensities were an indicator of the mitochondrial membrane potential.

Cell-cycle analysis. Cells were harvested, washed twice with PBS, fixed in $70 \%$ ethanol and stored at $4{ }^{\circ} \mathrm{C}$ overnight, then washed with PBS, incubated with RNase at $37^{\circ} \mathrm{C}$ for $30 \mathrm{~min}$ and stained with PI $(1 \mathrm{mg} / \mathrm{ml})$ in the presence of RNase A for $30 \mathrm{~min}$. Cell-cycle phase analysis was performed by using a FACScalibur flow cytometer.

Western blot analysis. Cells were lysed in western blotting lysis buffer at $4{ }^{\circ} \mathrm{C}$ for $30 \mathrm{~min}$. After $12000 \mathrm{~g}$ centrifugation for $15 \mathrm{~min}$, the protein content of supernatant was quantified using a BCA protein assay kit (Beyotime Institute of 
Biotechnology). Equal amounts of the protein samples were separated by SDSPAGE, and transferred to nitrocellulose membranes using an electro-blotting apparatus (Bio-Rad, Hercules, CA, USA). Then the membranes were blocked in blocking buffer (TBST plus 5\% skimmed milk), and incubated with primary antibodies overnight at $4{ }^{\circ} \mathrm{C}$. After that the membranes were washed with TBST and incubated with horseradish peroxidase-conjugated secondary antibodies for $1.5 \mathrm{~h}$ at $4{ }^{\circ} \mathrm{C}$. Protein expression was visualized using the chemoluminescence reagent (Millipore, Bedford, MA, USA) and detected on a photographic film.

Measurement of RAS activation. The activity of the Ras protein was determined by precipitating the GTP-bound forms of Ras using the RBD of Raf-1 as an activation-specific probe. ${ }^{27}$ Cells were lysed and the cleared lysate was subjected to a RAS-GTP assay as per the manufacturer's instructions (Upstate Biotechnology, Lake Placid, NY, USA). The amount of RAS in the bound fraction was determined by western blot analysis with the anti-Ras antibody.

siRNA transfection. Cells were plated in six-well plates at $1.5 \times 10^{5} \mathrm{cells} /$ well, grown for $24 \mathrm{~h}$, then transfected with $100 \mathrm{pmol}$ of siRNA for $6 \mathrm{~h}$ using Lipofectamine 2000 reagent and OPTIMEM reduced serum medium (Invitrogen, Carlsbad, CA, USA). The cells were assayed $48 \mathrm{~h}$ after transfection.

SPR biosensor analysis. SPR biosensor analysis was used to verify the binding of WA to Ras-GDP/GTP protein, which was analyzed by the Center for Bio-information Technology, Chinese Academy of Sciences Shanghai, using an SPR-based Biacore 3000 instrument. In brief, the protein was immobilized on a CM5 sensor chip in 7000 response units (RU) according to the standard primary amine-coupling procedures, the immobilization buffer and the running buffer was $2 \%$ DMSO in PBS. Equilibration of the base line was performed by a continuous flow of $2 \%$ DMSO through the chip surface for $1 \sim 2 \mathrm{~h}$. WA was diluted into different concentrations with a constant DMSO concentration of $2 \%$, and then injected into the protein binding channels at a flow rate of $10 \mathrm{ul} / \mathrm{min}$ followed by washing with the running buffer.

Molecular docking. The protein crystallographic structures were downloaded from the Protein Data Bank. Protein Protocol in Discovery Studio 2.5 was used to prepare the protein. Molecular docking was performed with program GOLD version 3.0.1. During GOLD docking, the default parameters of genetic algorithm (GA) were applied to search reasonable binding conformation and ChemScore function was used to evaluate docking results.

Mouse xenograft model. The mouse-xenograft model was established by injection of $2 \times 10^{6}$ cells s.c. into the right armpit of 5-week old BALB/c male athymic mice (National Rodent Laboratory Animal Resource, Shanghai, China). The mice were randomized into 5 groups (6-7 mice per group): vehicle control (1\% DMSO), $2.5 \mathrm{mg} / \mathrm{kg}$ Cisplatin, $20 \mathrm{mg} / \mathrm{kg}$ Cyclophosphamide and 5, 10, $20 \mathrm{mg} / \mathrm{kg}$ WA group when xenografts were palpable. Vehicle or drugs were administered intravenously everydays days until sacrifice; body weight and tumor size were measured and recorded at the same time. Tumor size was measured using electronic caliper, and the tumor volumes were calculated using the formula: length $\times$ width $^{2} / 2$. On 20 days, mice were killed; tumors were collected, weighed, and photographed. Tumor inhibition effect was calculated using the following equation: tumor suppression $(\%)=(1-\mathrm{T} / \mathrm{C}) \times 100$, where $\mathrm{T}$ is the average tumor weight of the treated group and $C$ is that of the control group. The institutional and national guidelines for the care and use of animals were followed and the Ethical Committee of the Second Military Medicine University approved the current study.

Immunohistochemical analysis. Tumors were harvested, fixed in $10 \%$ neutral buffered formalin at $4{ }^{\circ} \mathrm{C}$ for $24 \mathrm{~h}$, and then embedded in paraffin. Tumor slides were deparaffinized and rehydrated using xylene and alcohol; for immunoperoxidase labeling, endogenous peroxidase was blocked with $3 \%$ $\mathrm{H}_{2} \mathrm{O}_{2}$ for $10 \mathrm{~min}$ at room temperature. Primary antibodies were reacted with the tissue overnight in a humid chamber at $4{ }^{\circ} \mathrm{C}$ and washed with PBS. Then slides were incubated with horseradish peroxidase-conjugated secondary antibodies for $1.5 \mathrm{~h}$ at $4{ }^{\circ} \mathrm{C}$. Immunoreactive sites were visualized using 3,30-diaminobenzidine staining for $5 \mathrm{~min}$. Sections were counterstained with hematoxylin, dehydrated and mounted with coverslips. The slides were viewed under a Nikon H500S microscope (Nikon Inc, Melville, NY, USA). For the immunohistochemical quantification QC, five randomly images from each tumor were analyzed. The large necrotic areas in the xenograft were excluded from analysis.

\section{Conflict of Interest}

The authors declare no conflict of interest.

Acknowledgements. This research project was supported by the National Basic Research Program of China (973 Program) (2010CB833804) and the National Ocean 863 Project of the Ministry of Science and Technology of China (2011AA09070110).

1. Siegel R, Ward E, Brawley O, Jemal A. Cancer Statistics, 2011: the impact of eliminating socioeconomic and racial disparities on premature cancer deaths. CA Cancer J Clin 2011; 61: 212-236.

2. Reveiz L, Rueda JR, Cardona AF. Palliative endobronchial brachytherapy for non-small cell lung cancer. Cochrane Database Syst Rev 2012; doi:10.1002/14651858. CD004284.pub32012.

3. Voortman J, Lee JH, Killian JK, Suuriniemi M, Wang Y, Lucchi M et al. Array comparative genomic hybridization-based characterization of genetic alterations in pulmonary neuroendocrine tumors. Pro Natl Acad Sci USA 2010; 107: 13040-13045.

4. Molina JR, Yang P, Cassivi SD, Schild SE, Adjei AA. Non-small cell lung cancer: epidemiology, risk factors, treatment and survivorship. Mayo Clin Proc 2008; 83: 584-594.

5. Shen L, Li Z, Shen S, Niu X, Yu Y, Li Z et al. The synergistic effect of EGFR tyrosine kinase inhibitor gefitinib in combination with aromatase inhibitor anastrozole in non-small cell lung cancer cell lines. Lung Cancer 2012; 78: 193-200.

6. Alamgeer M, Ganju V, Watkins DN. Novel therapeutic targets in non-small cell lung cancer. Curr Opin Pharmacol 2013; 13: 394-401.

7. Sos ML, Dietlein F, Peifer M, Schöttle J, Balke-Want H, Müller $C$ et al. A framework for identification of actionable cancer genome dependencies in small cell lung cancer. Proc Natl Acad Sci USA 2012; 109: 17034-17039.

8. Downward J. Targeting RAS signalling pathways in cancer therapy. Nat Rev Cancer 2003; 3: $11-22$.

9. Cox AD, Der CJ. The dark side of Ras: regulation of apoptosis. Oncogene 2003; 22: 8999-9006.

10. Woessmann W, Chen X, Borkhardt A. Ras-mediated activation of ERK by cisplatin induces cell death independently of p53 in osteosarcoma and neuroblastoma cell lines. Cancer Chemother Pharmacol 2002; 50: 397-404.

11. Bacus SS, Gudkov AV, Lowe M, Lyass L, Yung Y, Komarov AP et al. Taxol-induced apoptosis depends on MAP kinase pathways (ERK and p38) and is independent of p53. Oncogene 2001; 20: 147-155.

12. Tang D, Wu D, Hirao A, Lahti JM, Liu L, Mazza B et al. ERK activation mediates cell cycle arrest and apoptosis after DNA damage independently of p53. J Biol Chem 2002; 277: 12710-12717.

13. Sun HF, Li XM, Meng L, Cui CM, Gao SS, Li CS et al. Asperolides A-C, tetranorlabdane diterpenoids from the marine alga-derived endophytic fungus Aspergillus wentii EN-48. J Nat Prod 2012; 75: 148-152.

14. Lv C, Sun W, Sun H, Wei S, Chen R, Wang B et al. Asperolide A, a marine-derived tetranorditerpenoid, induces $\mathrm{g} 2 / \mathrm{m}$ arrest in human nci-h460 lung carcinoma cells, is mediated by p53-p21 stabilization and modulated by ras/raf/mek/erk signaling pathway. Mar Drugs 2012; 11: 316-331.

15. Zhang Z, Miao L, Lv C, Sun H, Wei S, Wang B et al. Wentilactone B induces G2/M phase arrest and apoptosis via the Ras/Raf/MAPK signaling pathway in human hepatoma SMMC-7721 cells. Cell Death Dis 2013; 4: e657.

16. Zhang W, Liu HT. MAPK signal pathways in the regulation of cell proliferation in mammalian cells. Cell Res 2002; 12: 9-18.

17. Vogelstein B, Lane D, Levine AJ. Surfing the p53 network. Nature 2000; 408: 307-310.

18. Vousden KH, Lane DP. p53 in health and disease. Nat Rev Mol Cell Biol 2007; 8: 275-283.

19. Wu GS. The functional interactions between the p53 and MAPK signaling pathways. Cancer Biol Ther 2004; 3: 156-161.

20. Dulić V, Stein GH, Far DF, Reed SI. Nuclear accumulation of p21Cip1 at the onset of mitosis: A role at the G2/M-phase transition. Mol Cell Biol 1998; 18: 546-557.

21. Benhar M, Engelberg D, Levitzki A. ROS stress-activated kinases and stress signaling in cancer. EMBO Rep 2002; 3: 420-425.

22. Singh SV, Srivastava SK, Choi S, Lew KL, Antosiewicz J, Xiao D et al. Sulforaphaneinduced cell death in human prostate cancer cells is initiated by reactive oxygen species. J Biol Chem 2005; 280: 19911-19924.

23. Zhang R, Humphreys I, Sahu RP, Shi Y, Srivastava SK. In vitro and in vivo induction of apoptosis by capsaicin in pancreatic cancer cells is mediated through ROS generation and mitochondrial death pathway. Apoptosis 2008; 13: 1465-1478.

24. McLean L, Soto U, Agama K, Francis J, Jimenez R, Pommier $Y$ et al. Aminoflavone induces oxidative DNA damage and reactive oxidative species-mediated apoptosis in breast cancer cells. Int. J. Cancer 2008; 22: 1665-1674. 
25. Fleury $\mathrm{C}$, Mignotte $\mathrm{B}$, Vayssière $\mathrm{JL}$. Mitochondrial reactive oxygen species in cell death signalling. Biochimie 2002; 84: 131-141.

26. Kamata H, Hirata H. Redox Regulation of Cellular Signalling. Cell Signal 1999; 11: 1-14.

27. de Rooij J, Bos JL. Minimal Ras-binding domain of Raf1 can be used as an activationspecific probe for Ras. Oncogene 1997; 14: 623-625.

28. Kötting C, Kallenbach A, Suveyzdis Y, Wittinghofer A, Gerwert K. The GAP arginine finge movement into the catalytic site of Ras increases the activation entropy. Proc Natl Acad Sc USA 2008; 105: 6260-6265.

29. Oren M. Regulation of the p53 tumor suppressor protein. J Biol Chem 1999; 274: 36031-36034.

30. Ryan KM, Phillips AC, Vousden KH. Regulation and function of the p53 tumor suppressor protein. Curr Opin Cell Biol 2001; 13: 332-337.

31. Banin S, Moyal L, Shieh S, Taya Y, Anderson CW, Chessa L et al. Enhanced phosphorylation of p53 by ATM in response to DNA damage. Science 1998; 281: 1674-1677.

32. She QB, Chen N, Dong Z. ERKs and p38 kinase phosphorylate p53 protein at serine 15 in response to UV radiation. J Biol Chem 2000; 275: 20444-20449.

33. Vaseva AV, Moll UM. The mitochondrial p53 pathway. Biochim Biophys Acta 2009; 1787 414-420.

34. Miyashita T, Harigai M, Hanada M, Reed JC. Identification of a p53-dependent negative response element in the bcl-2 gene. Cancer Res 1994; 54: 3131-3135.

35. Miyashita T, Reed JC. Tumor suppressor p53 is a direct transcriptional activator of the human bax gene. Cell 1995; 80: 293-299.

36. Mihara M, Erster S, Zaika A, Petrenko O, Chittenden T, Pancoska P et al. p53 has a direct apoptogenic role at the mitochondria. Mol Cell 2003; 11: 577-590.

37. Chipuk JE, Kuwana T, Bouchier-Hayes L, Droin NM, Newmeyer DD, Schuler M et al. Direct activation of Bax by p53 mediates mitochondrial membrane permeabilization and apoptosis. Science 2004; 303: 1010-1014.

38. Jiang P, Du W, Wu M. p53 and Bad: remote strangers become close friends. Cell Res 2007; 17: 283-285.
39. Cuconati A, Mukherjee C, Perez D, White E. DNA damage response and MCL-1 destruction initiate apoptosis in adenovirus-infected cells. Genes Dev 2003; 17: 2922-2932.

40. Xia Z, Dickens M, Raingeaud J, Davis RJ, Greenberg ME. Opposing effects of ERK and JNK-p38 MAP kinases on apoptosis. Science 1995; 270: 1326-1331.

41. Eisenberg-Lerner A, Bialik S, Simon HU, Kimchi A. Life and death partners: apoptosis, autophagy and the cross-talk between them. Cell Death Differ 2009; 16: 966-975

42. Lowy DR, Willumsen BM. Function and regulation of Ras. Annu Rev Biochem 1993; 62 : 851-891.

43. Overmeyer $\mathrm{JH}$, Maltese WA. Death pathways triggered by activated Ras in cancer cells. Front Biosci 2011; 16: 1693-1713.

44. Davis MF, Vigil D, Campbell SL. Regulation of Ras proteins by reactive nitrogen species. Free Radic Biol Med 2011; 51: 565-575.

45. Cherfils J, Zeghouf M. Regulation of small GTPases by GEFs, GAPs, and GDIs. Physiol Rev 2013; 93: 269-309.

46. Rubio II, Wetzker R. A permissive function of phosphoinositide 3-kinase in ras activation mediated by inhibition of GTPase-activating proteins. Curr Biol 2000; 10: R883.

47. Hofer F, Berdeaux R, Martin GS. Ras-independent activation of Ral by a $\mathrm{Ca}(2+)$ dependent pathway. Curr Biol 1998; 8: 839-842.

48. Giaccone G. Clinical perspectives on platinum resistance. Drugs 2000; 59: 37-38

49. Stordal B, Davey M. Understanding cisplatin resistance using cellular models. IUBMB Life 2007; 59: 696-699.

(c) (i) $(\Theta$ Cell Death and Disease is an open-access journal published by Nature Publishing Group. This work is licensed under a Creative Commons Attribution-NonCommercialNoDerivs 3.0 Unported License. To view a copy of this license, visit http://creativecommons.org/licenses/by-nc-nd/3.0/

Supplementary Information accompanies this paper on Cell Death and Disease website (http://www.nature.com/cddis) 